\title{
Pengaruh Variasi Sludge-serbuk Kayu sebagai Penguat terhadap Sifat Mekanik Material Komposit Matriks Urea-Formaldehida
}

\author{
Deni S. Khaerudini* dan Muljadi \\ Pusat Penelitian Fisika - LIPI, \\ Kawasan PUSPIPTEK Serpong Tangerang \\ Telp. 021-7560570, Fax. 021-7560554
}

\begin{abstract}
Intisari
Material komposit papan partikel dibuat dari penguat berbasis lignoselulosa dan matriks resin ureaformaldehida. Pembuatan dilakukan dengan mencampur sludge, partikel kayu, dan matriks. Variabel komposisi berat kedua jenis penguat (sludge-partikel kayu), yaitu: 60:40, 70:30, dan 80:20, untuk komposisi matriks yaitu $8 \%, 10 \%$, dan $12 \%$ berat komposit. Setelah komposisi dicampur target kerapatan adalah $0,6 \mathrm{~g} / \mathrm{cm}^{3}$. Pembuatan dilakukan dengan metode mat-forming dengan ukuran cetakan $30 \mathrm{~cm}$ x $30 \mathrm{~cm}$. Kemudian dilakukan Hot-Press $15 \mathrm{kgf} / \mathrm{cm}^{2}$, suhu $150^{\circ} \mathrm{C}$, selama $15-25$ menit. Selanjutnya komposit diuji mekanik berupa uji elastisitas dan kuat patah mengacu standar JIS.A.5908-94 dan JIS.A.5905-94. Nilai densitas 0,56-0,70 g/ $\mathrm{cm}^{3}$, elastisitas 6213$12978 \mathrm{kgf} / \mathrm{cm}^{2}$, dan kuat patah $52-108 \mathrm{kgf} / \mathrm{cm}^{2}$.
\end{abstract}

KATA KUNCI: komposit, sludge, partikel kayu, urea-formaldehida, hot-press, mat-forming

\section{PENDAHULUAN}

Meningkatnya perkembangan kegiatan industri dan aktivitas lainnya akan membawa konsekuensi yang luas termasuk bahan limbah yang dihasilkan. Salah satu jenis limbah industri yang sampai saat ini masih sulit untuk ditangani adalah masalah limbah yang berasal dari industri pulp dan kertas. Agar limbah dari beberapa proses tersebut tidak menimbulkan dampak negatif, maka perlu pengelolaan yang lebih baik dengan memanfatkan kembali secara tepat dan bijaksana [1]. Salah satu upaya yang dapat dilakukan adalah dengan meningkatkan kegunaannya melalui perekayasaan material sebagai bahan interior berupa material papan partikel (papan komposit). Papan partikel (particleboard) adalah lembaran papan hasil pengemapaan panas pada tekanan dan suhu tertentu dengan campuran kayu atau bahan berlignoselulosa lainnya dengan perekat organik dan bahan lainnya [2].

Teknologi material komposit saat ini mengalami perkembangan ke penggunaan bahan alam sebagai komponen pembentuknya terutama penggunaan serat alam sebagai pengganti serat sintetis yang selama ini dipakai. Pembuatan papan partikel (papan komposit) dari limbah, selain dapat meningkatkan efisiensi pemanfaatan kayu juga dapat memecahkan masalah lingkungan akibat pembuangan limbah tersebut [3]. Dalam perkembangan dunia industri telah dikembangkan pembuatan komposit dengan menggunakan penguat alam yang pada sisi pembiayaan atau investasi akan lebih ekonomis [4]. Di Indonesia, potensi kayu sebagai filler sangat besar, terutama pemanfaatan limbah serbuk kayu dan sludge

*E-MAIL: deni@fisika.lipi.go.id (limbah lumpur padat pulp).

Dalam makalah ini dibahas proses pembuatan papan partikel (papan komposit) dengan memanfaatkan sludge (limbah lumpur padat pulp) dan serbuk kayu (acacia mangium) sebagai filler, dan sebagai matriks digunakan unsaturated polyester jenis thermosetting yaitu urea-formaldehida (UF) tipe interior dengan komposisi material yang divariasi, termasuk pengujian sifat mekanik dan kerapatan bahan sesuai target kerapatan papan tipe interior (medium density particleboard) berupa produk papan partikel (papan komposit) sebagai salah satu teknologi alternatif pemanfaatan limbah gergajian kayu dan sludge.

\section{DASAR TEORI}

Komposit merupakan suatu bahan hasil penggabungan dua atau lebih materi penyusun yang berbeda secara makroskopik yang tidak larut satu dengan yang lainnya [5]. Tujuan penggabungan material ini adalah untuk menemukan material baru yang mempunyai sifat antara material penyusunnya yang tidak akan diperoleh jika material penyusunnya berdiri sendiri.

Komposit merupakan bahan yang terdiri atas serat yang diselubungi oleh matriks, biasanya berupa polimer, logam, atau keramik. Serat (penguat) biasanya berupa bahan dengan kekuatan dan modulus yang tinggi yang berperan sebagai penyandang beban utama. Sedangkan matriks harus menjaga serat tetap dalam lokasi dan orientasi yang dikehendaki. Matriks juga berfungsi sebagai media transfer beban antar serat, pelindung serat dari kerusakan karena pengaruh lingkungan (environtment damage) sebelum, ketika, dan setelah proses pembuatan komposit, serta melindungi dari pengaruh abrasif antar 


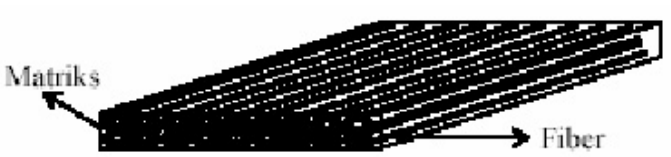

Gambar 1: Komposit serat

serat.

Komposit dengan matriks polimer (PMCs) merupakan komposit yang paling banyak digunakan sebagai alternatif logam. Secara umum peroses pembuatan papan komposit/papan partikel biasanya direkat dengan resin thermosetting, yaitu: Phenolformaldehida digunakan untuk tipe eksterior dan Urea-formaldehida (UF) untuk tipe interior. Tipe interior dengan batas ketahanan air dapat diproduksi dengan meningkatkan penggunaan resin urea dan kadang polyphenols alami (tanin) dicampur dengan resin sintetis [6].

Komposit dibentuk dari dua jenis material yang berbeda, yaitu: penguat (reinforcement), yang mempunyai sifat kurang duktil tetapi lebih rigid serta lebih kuat, dan matriks umumnya lebih duktil tetapi mempunyai kekuatan dan rigiditas yang lebih rendah. Secara umum terdapat 3 jenis komposit berdasarkan penguat yang digunakannya, antara lain:

\section{Komposit Serat (Fibrous Composites)}

Merupakan jenis komposit yang hanya terdiri dari satu lamina atau satu lapisan yang menggunakan penguat berupa serat (fiber). Fiber yang digunakan bisa berupa glass fibers, carbon fibers, aramid fibers (poly aramide), dan sebagainya. Fiber ini bisa disusun secara acak maupun dengan orientasi tertentu bahkan bisa juga dalam bentuk yang lebih kompleks seperti anyaman.

\section{Komposit Laminat (Laminated Composites)}

Merupakan jenis komposit yang terdiri dari dua lapis atau lebih yang digabung menjadi satu dan setiap lapisnya memiliki karakteristik sifat sendiri.
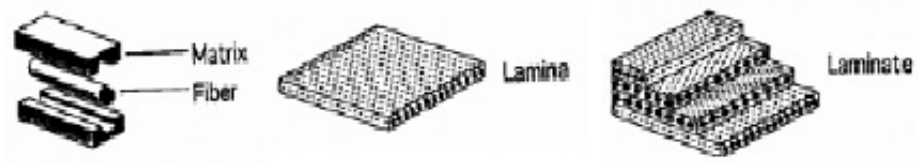

Gambar 2: Komposit laminat

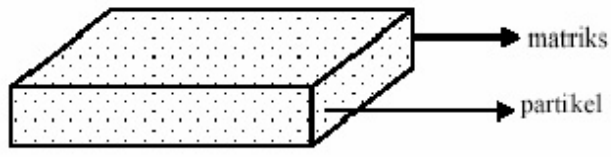

Gambar 3: Komposit partikel

\section{Komposit Partikel (Particulalate Composites)}

Merupakan komposit yang menggunakan partikel/serbuk sebagai penguatnya dan terdistribusi secara merata dalam matriksnya.

Penambahan filler ke dalam matriks bertujuan meningkatkan sifat-sifat mekanis melalui penyebaran tekanan yang efektif di antara serat dan matriks. Selain itu penambahan filler akan mengurangi biaya disamping memperbaiki beberapa sifat produknya.

Serbuk kayu memiliki kelebihan sebagai filler bila dibandingkan dengan filler mineral seperti mika, kalsium karbonat, dan talk, yaitu: temperatur proses lebih rendah (kurang dari $400^{\circ} \mathrm{F}$ ) sehing ga mengurangi biaya energi, dapat terdegradasi secara alami, berat jenisnya jauh lebih rendah berdampak pada biaya per volume yang lebih murah, gaya geseknya rendah se- hingga tidak merusak peralatan pada proses pembuatan, serta berasal dari sumber yang dapat diperbaharui [7].

Industri pulp dan kertas umumnya menghasilkan limbah padat yang berkadar air tinggi, berbentuk sludge. sludge merupakan lumpur hasil pengendapan yang berasal dari UPL (unit pengolahan limbah) industri pulp dan kertas. Secara garis besar, sludge yang berasal dari industri pulp dan kertas terdiri dari padatan tersuspensi yaitu terutama serat dan sisa sisa hancuran serat (serat yang tidak dalam bentuk utuh), bahan organik dalam bentuk partikel koloid yang berasal dari bahan kayu sendiri.

\section{Kekuatan Bending}

Untuk mengetahui kekuatan bending suatu material, dapat dilakukan dengan pengujian bending terhadap material tersebut [8]. Data hasil pengujian kemudian dilakukan analisa MOR (Modulus of Rupture) dengan menggunakan Persamaan.1.

$$
\sigma_{b}=\frac{3 P L}{2 b h^{2}}
$$

Jika defleksi maksimum yang terjadi lebih dari $10 \%$ dari jarak antar penumpu (L), kekuatan bendingnya dapat dihitung den- 

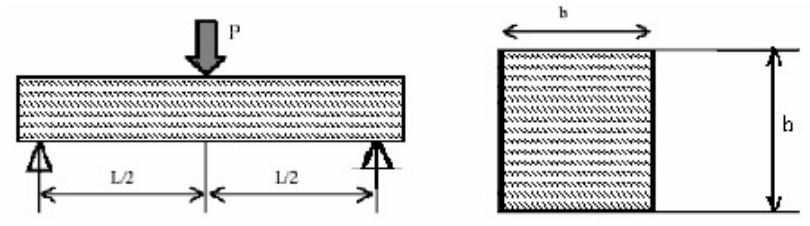

Gambar 4: Potongan penampang papan komposit

gan Persamaan.2 yang lebih akurat daripada Persamaan.1.

$$
\sigma_{b}=\frac{3 P L}{2 b h^{2}}\left[1+4\left(\frac{\delta}{L}\right)\right]
$$

Modulus elastisitas (MOE, Modulus of Elasticity) bendingnya dapat dirumuskan dengan persamaan:

$$
E_{b}=\frac{1}{4} \times \frac{L}{b h^{3}} \times \frac{P}{\delta}
$$

Sampel uji berukuran $20 \mathrm{~cm} \times 5 \mathrm{~cm}$. Pengujian dilakukan dengan menggunakan alat universal testing machine (UTM) dengan panjang bentang (L) 15,2 cm. Pembebanan dilakukan pada posisi tengah bentang sampel uji. Skema uji bending papan partikel dapat dilihat pada Gambar 4 berikut: Untuk uji kerapatan (densitas) material, sampel uji yang digunakan berukuran $10 \mathrm{~cm} \times 10 \mathrm{~cm}$. Dari hasil pengukuran berat dan volume setiap sampel uji, kemudian dilakukan perhitungan kerapatan bahannya dengan menggunakan persamaan:

$$
\rho=\frac{m}{V}
$$

\section{METODOLOGI PENELITIAN}

Bahan baku yang digunakan dalam pembuatan papan partikel (papan komposit) antara lain: sludge, limbah lumpur padat hasil pengolahan pabrik pulp dan kertas (PT.Indah Kiat, Tangerang) dengan kadar air 1,68\% dan panjang $1-8 \mathrm{~mm}$, partikel kayu (acacia mangium) dengan kadar air 0,55\% dan panjang 5- $20 \mathrm{~mm}$, dan perekat urea-formaldehida (Pamolite Adhesive Industry, Probolinggo - Jawa Timur). Diagram alir pembuatan papan partikel ditunjukkan pada Gambar 5.

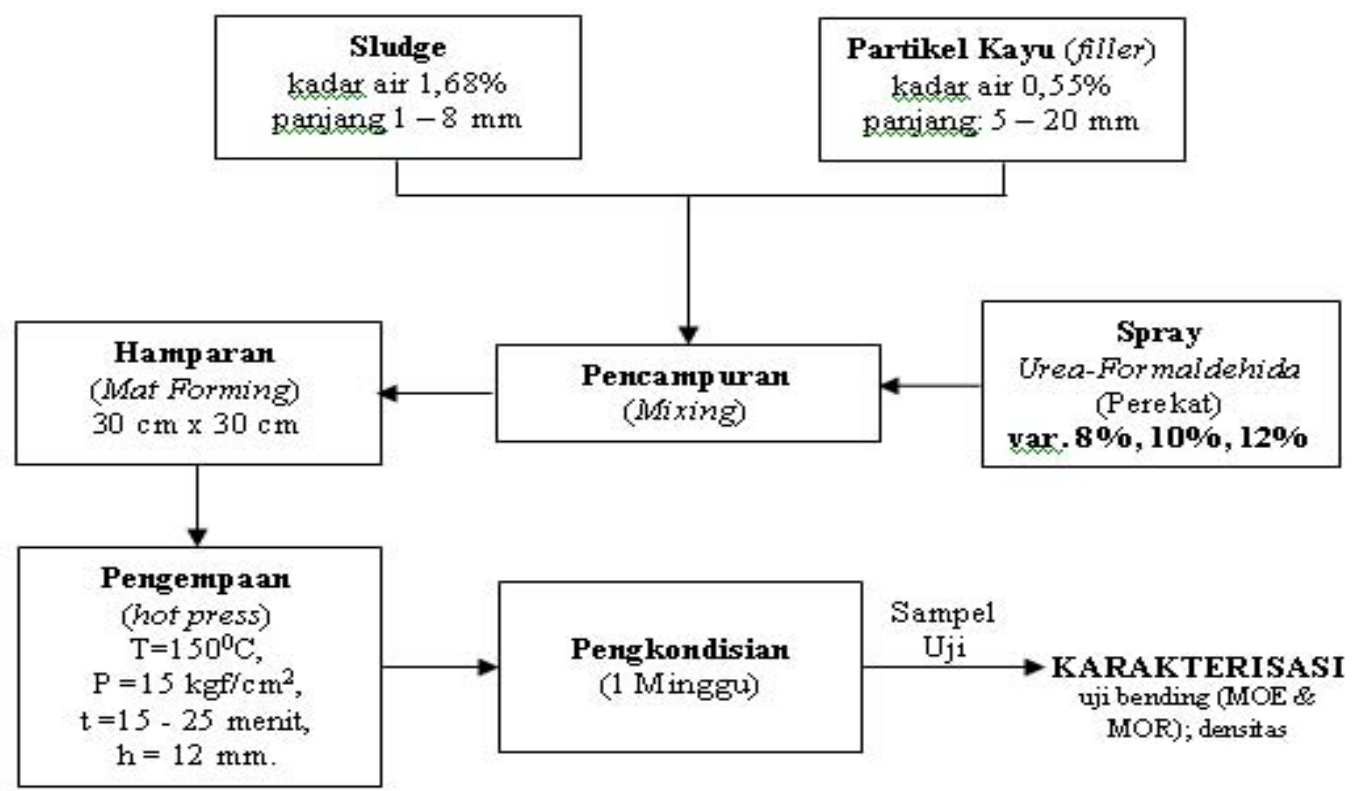

Gambar 5: Diagram alir proses pembuatan papan partikel (papan komposit)

Pengujian bending dilakukan untuk memperoleh nilai modulus elastisitas (MOE) dan modulus patah (MOR) dengan preparasi sampel (dipotong-potong) terlebih dahulu sesuai dengan standar uji JIS A.5908-94 (particle board) dan JIS A.5905-94 (fiber board) dengan alat Universal Testing Machine (UTM). Kerapatan bahan (densitas), menyatakan besarnya luas kontak antara partikel dan perekat, merupakan ukuran yang menyatakan bobot papan partikel persatuan volume. Hot press tergantung pada jenis kayu, untuk kayu berat jenis rendah $7 \mathrm{kgf} / \mathrm{cm}^{2}-10 \mathrm{kgf} / \mathrm{cm}^{2}$, untuk kayu berat jenis sedang $10 \mathrm{kgf} / \mathrm{cm}^{2}-15 \mathrm{kgf} / \mathrm{cm}^{2}$, dan $15 \mathrm{kgf} / \mathrm{cm}^{2}-17 \mathrm{kgf} / \mathrm{cm}^{2}$ untuk kayu berat jenis tinggi [2]. 


\section{HASIL DAN DISKUSI}

Dari hasil uji bending terhadap papan partikel (papan komposit) diperoleh pola grafik pada Gambar 6 .

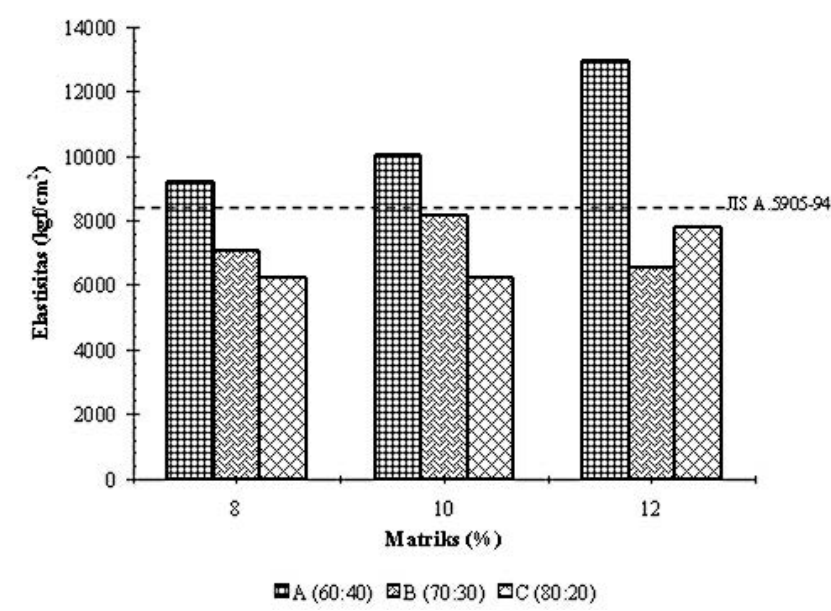

Gambar 6: Grafik Elastisitas, hubungan \% Matriks terhadap komposisi sludge dan serat kayu

Nilai modulus elastisitas (MOE) dan modulus patah (MOR) diperoleh dengan pengujian sampel uji papan partikel menggunakan standar JIS A.5908-94 dan JIS A.5905-94. Dilihat pada grafik di atas (Gambar 6) bahwa hasil pengukuran modulus elastisitas berkisar antara $6.213-12.978 \mathrm{kgf} / \mathrm{cm}^{2}$. Berdasarkan JIS A.5905-94 nilai minimum MOE adalah $8.200 \mathrm{kgf} / \mathrm{cm} 2$ untuk papan partikel tipe 5 kualitas MDP (medium density particleboard). Jadi, dari ketiga sampel uji hanya komposisi sampel A dengan jumlah perekat 8\%, 10\%, dan $12 \%$ yang memenuhi standar. Sedangkan untuk standar JIS A.5908-94 nilai minimum MOE yang diijinkan adalah $20.400 \mathrm{kgf} / \mathrm{cm}^{2}$ untuk papan komposit tipe 8 , terlihat dengan jelas bahwa seluruh sampel uji tidak ada yang memenuhi berdasarkan standar uji JIS A.5908-94.

Dari hasil pengujian modulus patah (MOR) dapat dilihat pada Gambar 7, hasil pengukuran berkisar antara $52-108$ $\mathrm{kgf} / \mathrm{cm}^{2}$. Berdasarkan JIS A.5908-94, nilai minimum MOR sebesar $82 \mathrm{kgf} / \mathrm{cm}^{2}$ untuk papan komposit tipe 8. Dapat dilihat pada grafik diatas bahwa nilai MOR pada sampel uji yang memenuhi standar adalah hanya pada komposisi sampel A dengan jumlah perekat $8 \%, 10 \%$, dan $12 \%$. Jika berdasarkan standar JIS A.5905-94, semua komposisi sampel uji memenuhi standar yang diijinkan, dengan nilai minimum MOR sebesar $51 \mathrm{kgf} / \mathrm{cm}^{2}$ untuk papan komposit tipe 5 pada kualitas MDP.

Dilihat pada grafik-grafik di atas (Gambar 6 dan 7), terlihat dengan jelas modulus elastisitas dan kekuatan patah terbesar terdapat pada sampel dengan komposisi filler sludge : serbuk kayu $=60: 40$ dan perekat $12 \%$. Sampel uji tersebut, menahan beban tekan dan tarik lebih baik, karena serat (whisker) dari serbuk kayu pada penampang spesimen, sepenuhnya menahan beban yang diterima. Papan partikel yang dibuat dari serat akan lebih baik daripada yang dibuat dari serbuk karena ukuran serat lebih besar daripada serbuk

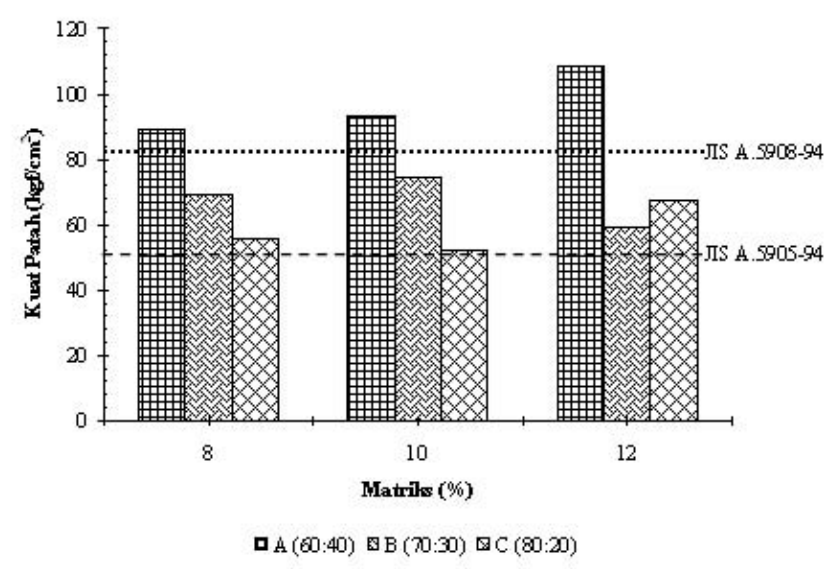

Gambar 7: Grafik Kuat Patah, hubungan \% Matriks terhadap komposisi sludge dan serat kayu

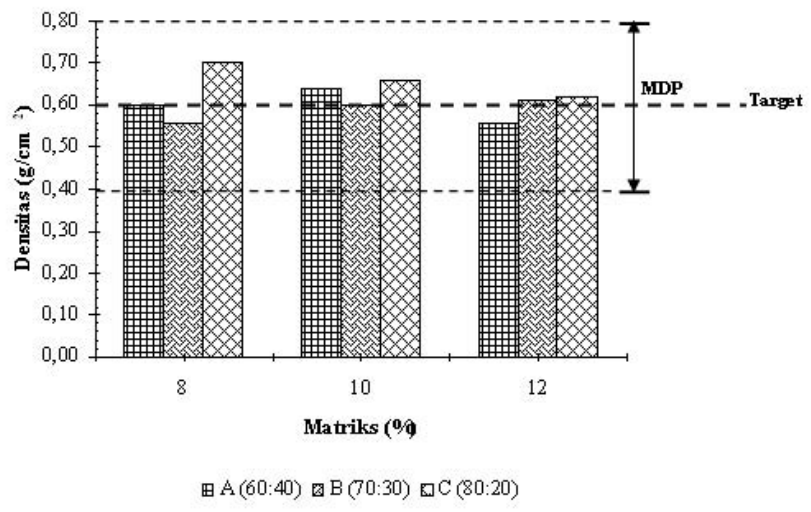

Gambar 8: Grafik Densitas, hubungan \% Matriks terhadap komposisi sludge dan serat kayu

[9]. Karena itu, papan partikel struktural dibuat dari partikel yang relatif panjang dan relatif lebar. Komposit yang berkualitas tinggi hanya dapat dicapai bila serbuk kayu terdistribusi dengan baik di dalam matriks. Dalam kenyataannya, afinitas antara serbuk kayu dengan plastik sangat rendah karena kayu bersifat hidrofilik sedangkan plastik bersifat hidrofobik. Akibatnya komposit yang terbentuk memiliki sifat-sifat pengaliran dan moldability yang rendah dan pada gilirannya dapat menurunkan kekuatan bahan [4]. Dari hasil pengukuran nilai kerapatan (density) seluruh sampel uji dapat dilihat pada Gambar 8 di atas, berkisar antara $0,56-0,70 \mathrm{~g} / \mathrm{cm}^{3}$. Jadi, nilai densitas yang diperoleh ternyata sesuai dengan target kerapatan maka seluruh material uji papan komposit ini dapat digolongkan sebagai papan partikel (material komposit) berkerapatan sedang (medium density particleboard). Perbandingan antara kerapatan atau berat jenis papan partikel dengan berat jenis kayu harus lebih dari satu, yaitu sekitar 1,3 agar mutu papan partikelnya baik. Pada keadaan tersebut proses pengempaan berjalan optimal sehingga kontak antar partikel baik. Tetapi kualitas papan partikel (particle board) sangat dipengaruhi oleh bahan baku yang digunakan. 


\section{SIMPULAN}

Limbah sludge dan partikel kayu dapat dimanfaatkan sebagai papan partikel (subtitusi papan konvensional) dan termasuk kategori papan partikel (komposit) interior (mutu II), yaitu papan partikel yang dalam penggunannya tidak memer- lukan sifat ketahanan terhadap kelembaban tinggi. Material komposit komposisi sampel uji A dengan jumlah perekat $12 \%$ merupakan komposisi sampel yang terbaik dan penambahan filler memberikan pengaruh yang signifikan terhadap sifat mekanik material komposit papan komposit.
[1] Lasino, 'Pengembangan Bahan Bangunan Ekologis dalam Menunjang Pembangunan ke-PU-an', Orasi APU, Departemen PU, Jakarta (2005)

[2] FAO, Plywood and Other Wood Based Panels, Food \& Agricultural Organization. Rome: 46 - 122 (1966).

[3] Setyawati, D. , Thesis, Program Pasca Sarjana-S3, Institut Pertanian Bogor, Bogor (2003).

[4] Han, G.S. , Disertasi, Kyoto: Kyoto University. Departement Of Wood Science and Technology, Faculty of Agriculture (1990).

[5] Schwartz, Composite Materials Handbook, McGraw-Hill Book Company, New York, USA (1984).

[6] Tsoumis, G. , Science and Technology of Wood: Structure, Prop- erties, Utilization, Van Nostrand Reinhold, New York(1991).

[7] Strak, N.M. \& Berger, M.J. , Fourth International Conference on Woodfiber-Plastic Composites. Madison, 12 -14 Mei 1997. Wisconsin: Forest Product Sociaty. 134-143 (1997).

[8] Gibson, O. F., Principle of Composite Materials Mechanics, McGraw-Hill Inc., New York, USA (1994).

[9] Sutigno, P., Teknologi Papan Partikel Datar, Pusat Penelitian dan Pengembangan Hasil Hutan dan Sosial Ekonomi Kehutanan, Bogor (1994).

[10] — - Japanese Industrial Standard Particleboard $5908 \mathrm{~A}$ and 5905 A, Japanese Standard Association, Japan, (1994). 